\title{
Efektivitas Analgesik Pascaoperasi pada Pasien Pediatrik di Ruang Pemulihan RSUP Dr. Hasan Sadikin Bandung Periode Juni-November 2018
}

\author{
Bernadeth, Ezra Oktaliansah, Indriasari \\ Departemen Anestesiologi dan Terapi Intensif \\ Fakultas Kedokteran Universitas Padjadjaran/RSUP Dr. Hasan Sadikin Bandung
}

\begin{abstract}
Abstrak
Nyeri merupakan pengalaman sensorik dan emosional yang tidak menyenangkan. Penyebab utama nyeri akut pada anak adalah prosedur pembedahan, trauma, dan penyakit akut. Penilaian nyeri merupakan bagian penting dari manajemen nyeri. Penelitian ini bertujuan mengetahui efektivitas analgesik pascaoperasi pada pasien pediatrik di ruang pemulihan RSUP Dr. Hasan Sadikin Bandung periode Juni-November 2018. Penelitian menggunakan metode deskriptif observasional prospektif terhadap 471 pasien pediatrik pascaoperasi di ruang pemulihan. Subjek penelitian dikelompokkan berdasar atas jenis operasi yang menyebabkan nyeri ringan, sedang, dan berat. Jenis analgesik pascaoperasi yang diberikan dan penilaian nyeri selama di ruang pemulihan dicatat untuk melihat efektivitas analgesik pascaoperasi tersebut. Dari hasil penelitian efektivitas analgesik pascaoperasi pada jenis operasi nyeri ringan sebanyak 181 pasien $(99,5 \%)$, jenis operasi nyeri sedang sebanyak 231 pasien $(98,7 \%)$, dan pada jenis operasi nyeri berat sebanyak 53 pasien $(96,4 \%)$. Simpulan penelitian ini adalah efektivitas analgesik pascaoperasi pada pasien pediatrik di RSUP Dr. Hasan Sadikin Bandung masih kurang efektif karena belum memenuhi target rumah sakit 100\% bebas nyeri dan pemberian analgesik juga belum efisien karena masih banyak terdapat ketidaksesuaian antara pilihan analgesik dan derajat nyeri.
\end{abstract}

Kata kunci: Efektivitas analgesik pascaoperasi, nyeri pascaoperasi, pediatrik

\section{Effectiveness of Post-Operative Analgesia on Pediatric Patients in the recovery room of Dr. Hasan Sadikin General Hospital Bandung from June to November 2018}

\begin{abstract}
Pain is an unpleasant sensory and emotional experience. Pain assessment is an important part of pain management. The main causes of acute pain in children are surgical procedures, trauma, and acute diseases. This study aimed to study the effectuIveness of postoperative analgesics in pediatric patients in the recovery room of Dr. Hasan Sadikin General Hospital Bandung from June to November 2018. This was a prospective observational descriptive study on 471 postoperative pediatric patients in recovery rooms. The research subjects were grouped based on the type of surgery pain, i.e. mild, moderate, and severe. The type of postoperative analgesics given and assessment of pain during the stay in the recovery room were recorded to see the effectiveness of the postoperative analgesic drug. From the results of the study it was identified that the of postoperative analgesics was effective for 181 patients $(99.5 \%)$ in the mild pain surgery group, for 231 patients (98.7\%) in the moderate pain surgery, and for 53 patients (96.4\%) in severe pain surgery. It is concluded that the postoperative analgesics provided to pediatric patients at Dr. Hasan Sadikin General Hospital Bandung is still less effective because it has not met the target of $100 \%$ pain free set by the hospital and that analgesic administration is also not efficient because there are still many discrepancies in analgesic choices and the degree of pain.
\end{abstract}

Keywords: Effectiveness of postoperative analgesics, postoperative pain, pediatrics

Korespondensi: Bernadeth, dr., SpAn, Departemen Anestesiologi dan Terapi Intensif Fakultas Kedokteran Universitas Padjadjaran/RSUP Dr. Hasan Sadikin Bandung, Jl. Pasteur No. 38 Bandung 40161, Tlpn 022 2038285, Email bernadeth. darien2012@gmail.com 


\section{Pendahuluan}

Nyeri telah didefinisikan oleh International Assocoation for the Study of Pain (IASP) sebagai pengalaman sensorik dan emosional yang tidak menyenangkan terkait dengan kerusakan jaringan yang aktual atau potensial. Nyeri akut merupakan salah satu rangsangan paling umum dialami anak-anak yang terjadi akibat cedera, penyakit, atau prosedur medis. Dampak dan persepsi rasa sakit juga dipengaruhi oleh latar belakang perkembangan, lingkungan, dan sosial budaya pasien. Rasa sakit yang tidak diobati akan memberikan efek negatif jangka panjang pada sensitivitas rasa sakit, fungsi kekebalan tubuh, neurofisiologi, sikap, dan perilaku perawatan kesehatan. ${ }^{1,2}$

Penatalaksanaan nyeri dapat dilakukan dengan cara/metode farmakologis maupun non-farmakologi. RSUP Dr. Hasan Sadikin Bandung telah menerapkan Standar Prosedur Operasional (SPO) berdasar atas Keputusan Direktur Utama RSUP Dr. Hasan Sadikin Bandung Nomor HK.02.04/8013/1040 II/2017 Tanggal 12 Januari 2017 tentang Panduan Manajemen Nyeri di RSUP Dr. Hasan Sadikin Bandung yang bertujuan sebagai acuan bagi dokter dan perawat dalam penerapan langkah-langkah melakukan skrining atau evaluasi nyeri untuk mengindentifikasi rasa nyeri yang dirasakan pasien. ${ }^{3}$

Standar pemberian analgesik pascaoperasi di RSUP Dr. Hasan Sadikin Bandung saat ini adalah pemberian analgesik sistemik dan regional sesuai dengan derajat nyeri pasien. Salah satu yang sangat berpengaruh terhadap keberhasilan penanganan nyeri pascaoperasi adalah evaluasi terhadap efek terapi nyeri yang kita berikan, serta tindak lanjut dari hasil evaluasi tersebut.

Tujuan penelitian ini adalah mengetahui efektivitas analgesik pada pasien pediatrik pascaoperasi yang mengalami nyeri di ruang pemulihan.

\section{Subjek dan Metode}

Penelitian ini merupakan penelitian deskriptif observasional yang dilakukan prospektif dengan teknik pengambilan data melalui pengamatan langsung pada pasien. Subjek penelitian adalah semua pasien pediatrik pascaoperasi di ruang pemulihan RSUP Dr. Hasan Sadikin Bandung pada bulan Juni 2018 hingga November 2018. Kriteria inklusi pada penelitian ini adalah pasien pediatrik yang telah menjalani operasi dan masuk ke ruang pemulihan. Kriteria eksklusi tidak ditemukan pada penelitian ini.

Penentuan besar sampel dipergunakan populasi terjangkau selama 6 (enam) bulan dari bulan Juni hingga November. Penelitian dilakukan setelah mendapatkan persetujuan dari Komite Etik Penelitian Kesehatan RSUP Dr. Hasan Sadikin Bandung/Fakultas Kedokteran Universitas Padjadjaran No: LB.04.01/A05/ EC/225/VII/2018.

Pasien pediatrik yang masuk ke ruang pemulihan pascaoperasi dicatat identitas, jenis operasi berdasar atas skala nyeri, dan obat analgesik pascaoperasi yang digunakan. Penilaian skala nyeri menggunakan neonatal infant pain scale (NIPS), visual analogue scale (VAS)/verbal rating scale (VRS), face, legs, activity, cry, and consolability scale (FLACC) yang dilakukan selama 2 jam di ruang pemulihan. Penilaian nyeri pada usia neonatus-1 tahun digunakan NIPS skor, pada usia $>1-6$ tahun digunakan FLACC skor, dan pada usia $>6-18$ tahun digunakan VAS/ VRS skor. Efektifivas analgesik pascaoperasi dinilai menggunakan skala nyeri dengan skala $<4$ dianggap efektif dan $\geq 4$ dianggap tidak efektif. Pasien dengan skala nyeri $\geq 4$ diberikan analgesik rescue dengan opioid (Fentanil).

Panduan penatalaksanaan nyeri berdasar atas derajat nyeri sesuai Standar Prosedur Operasional RSUP Dr. Hasan Sadikin Bandung bahwa analgesik pada pascaoperasi yang diberikan pada nyeri ringan menggunakan analgesik pascaoperasi non-opioid, nyeri sedang mempergunakan kombinasi opioid lemah dan non-opioid, dan pada nyeri berat menggunakan kombinasi opioid kuat dan nonopioid/anestesi lokal dengan target bebas nyeri $100 \%$.

Data hasil observasi pasien dikelompokkan 
Tabel 1 Karakteristik Umum Subjek Penelitian

\begin{tabular}{|c|c|}
\hline Variabel & $\mathrm{n}=471$ \\
\hline \multicolumn{2}{|l|}{ Usia (tahun) } \\
\hline Mean \pm Std & $8,43 \pm 5,650$ \\
\hline Median & 8,00 \\
\hline Range (min.-maks.) & $0,01-18,00$ \\
\hline \multicolumn{2}{|l|}{ Jenis operasi } \\
\hline Nyeri ringan & $182(38,6 \%)$ \\
\hline Nyeri sedang & $234(49,7 \%)$ \\
\hline Nyeri berat & $55(11,7 \%)$ \\
\hline \multicolumn{2}{|c|}{ Skala nyeri pascaoperasi } \\
\hline Mean \pm Std & $1.49 \pm 0.693$ \\
\hline Median & 1.00 \\
\hline Range (min.-maks.) & $0,00-6,00$ \\
\hline \multicolumn{2}{|l|}{ Analgesik pascaoperasi } \\
\hline Tidak & $1(0,2 \%)$ \\
\hline Fentanil drip & $3(0,6 \%)$ \\
\hline Kaltrofen supp & $4(0,8 \%)$ \\
\hline Kaudal & $4(0,8 \%)$ \\
\hline Kombinasi A & $143(30,4 \%)$ \\
\hline Kombinasi B & $5(1,1 \%)$ \\
\hline Kombinasi $\mathrm{C}$ & $32(6,8 \%)$ \\
\hline Parasetamol & $279(59,2 \%)$ \\
\hline \multicolumn{2}{|c|}{$\begin{array}{l}\text { Keterangan: untuk data kategorik disajikan dengan } \\
\text { frekuensi dan persentase, sedangkan data } \\
\text { numerik disajikan dengan rerata, median, } \\
\text { standar deviasi dan range. Kombinasi A } \\
\text { adalah kombinasi petidin dengan keterolak } \\
\text { IV, kombinasi B adalah petidin dan } \\
\text { parasetamol IV, kombinasi C adalah } \\
\text { kaudal dengan parasetamol IV }\end{array}$} \\
\hline
\end{tabular}

sesuai dengan variabel penelitian, kemudian diolah secara deskriptif dengan bantuan program statistical product and service solution (SPSS) versi 24.0 for windows.

\section{Hasil}

Penelitian dilakukan terhadap 471 pasien pediatrik yang telah menjalani operasi elektif maupun emergensi dan memenuhi kriteria inklusi. Tidak ada data yang dieksklusikan. Penelitian ini dilakukan di ruang pemulihan kamar operasi RSUP Dr. Hasan Sadikin yang beralamat di Jl. Pasteur no. 38 Bandung. Usia rerata pasien adalah $8,43 \pm 5,650$ tahun.

Pada penelitian ini jenis operasi terbanyak yang dilakukan adalah jenis operasi yang menghasilkan derajat nyeri sedang sebanyak 234 pasien $(49,7 \%)$. Skala nyeri rerata pasien adalah $1,49 \pm 0,693$. Jenis analgesik terbanyak yang digunakan adalah Parasetamol sebanyak 279 pasien $(59,2 \%)$. Sedangkan yang paling sedikit digunakan adalah Fentanil drip sebanyak 3 (0,6\%; Tabel 1).

Gambaran efektivitas analgesik terhadap jenis operasi didapatkan bahwa sebanyak 465 pasien $(98,7 \%)$ mengalami nyeri pascaoperasi dengan skala nyeri <4, sedangkan masih terdapat 6 pasien $(1,3 \%)$ yang mengalami nyeri dengan skala nyeri pascaoperasi $\geq 4$ (Tabel 2).

Gambaran mengenai efektivitas analgesik pascaoperasi berdasar atas rentang usia terhadap jenis operasi didapatkan pada pasien dengan rentang usia neonatus-1 tahun sebanyak 126 pasien (99,2\%) efektif dengan efektivitas $100 \%$ pada nyeri ringan dan nyeri berat namun tidak efektif pada 1 pasien $(1,5 \%)$ dengan jenis operasi nyeri sedang. Pada pasien dengan rentang usia 2-6 tahun didapatkan efektivitas $100 \%$ baik pada penanganan nyeri ringan, sedang, maupun berat yang diberikan. Pada pasien dengan

Tabel 2 Gambaran Efektivitas Analgesik Pascaoperasi terhadap Jenis Operasi

\begin{tabular}{lcccc}
\hline \multirow{3}{*}{ Efektivitas } & \multicolumn{3}{c}{ Kelompok Jenis Operasi } & \multirow{2}{*}{ Total } \\
\cline { 2 - 4 } & $\begin{array}{c}\text { Nyeri Ringan } \\
\mathbf{n = 1 8 2}\end{array}$ & $\begin{array}{c}\text { Nyeri Sedang } \\
\mathbf{n = 2 3 4}\end{array}$ & $\begin{array}{c}\text { Nyeri Berat } \\
\mathbf{n = 5 5}\end{array}$ & \\
\hline Efektif & $181(99,5 \%)$ & $231(98,7 \%)$ & $53(96,4 \%)$ & $465(98,7 \%)$ \\
Tidak efektif & $1(0,5 \%)$ & $3(1,3 \%)$ & $2(3,6 \%)$ & $6(1,3 \%)$ \\
\hline
\end{tabular}

Keterangan: untuk data kategorik disajikan dengan jumlah/frekuensi dan persentase, sedangkan data numerik disajikan dengan rerata, median, standar deviasi, dan range 
Tabel 3 Gambaran Rentang Usia dan Efektivitas Analgesik Pascaoperasi terhadap Jenis Operasi

\begin{tabular}{lcccccc}
\hline \multirow{2}{*}{ Jenis Operasi } & \multicolumn{2}{c}{ Neonatus s.d. 1 Tahun } & \multicolumn{2}{c}{ 2-6 Tahun } & \multicolumn{2}{c}{ 7-8 Tahun } \\
\cline { 2 - 7 } & Efektif & $\begin{array}{c}\text { Tidak } \\
\text { Efektif }\end{array}$ & Efektif & $\begin{array}{c}\text { Tidak } \\
\text { Efektif }\end{array}$ & Efektif & $\begin{array}{c}\text { Tidak } \\
\text { Efektif }\end{array}$ \\
\hline Nyeri ringan & $43(100 \%)$ & $0(0,0 \%)$ & $25(100 \%)$ & $0(0,0 \%)$ & $113(99,1 \%)$ & $1(0,9 \%)$ \\
Nyeri sedang & $63(98,4 \%)$ & $1(1,5 \%)$ & $23(100 \%)$ & $0(0,0 \%)$ & $145(98,6 \%)$ & $2(1,4 \%)$ \\
Nyeri berat & $20(100 \%)$ & $0(0,0 \%)$ & $4(100 \%)$ & $0(0,0 \%)$ & $29(93,5 \%)$ & $2(6,5 \%)$ \\
Total & $126(99,2 \%)$ & $1(0,78 \%)$ & $52(100 \%)$ & $0(0,0 \%)$ & $287(98,3 \%)$ & $5(1,7 \%)$ \\
\hline
\end{tabular}

Keterangan: untuk data kategorik disajikan dengan jumlah/frekuensi dan persentase, sedangkan data numerik disajikan dengan rerata, median, standar deviasi, dan range

rentang usia 7-18 tahun terdapat 287 pasien $(98,3 \%)$ efektif, dan sebanyak 5 pasien $(1,7 \%)$ tidak efektif terhadap analgesik pascaoperasi yang diberikan (Tabel 3).

Jenis analgesik non-opioid digunakan tidak hanya pada jenis operasi derajat nyeri ringan, namun terhadap operasi derajat nyeri sedang dan berat. Efektivitasnya terhadap jenis operasi nyeri sedang sebanyak 98,5\%. Efektivitas kombinasi opioid lemah dengan non-opioid digunakan terutama pada jenis operasi derajat nyeri sedang sebanyak 98,8\%. Kombinasi jenis analgesik ini masih digunakan juga pada operasi derajat nyeri ringan efektif sebanyak $97,9 \%$ dan derajat nyeri berat efektif sebanyak 85,7\%. Efektivitas kombinasi opioid kuat dengan non-opioid atau anestesi lokal sebanyak 100\% (Tabel 4).

Jenis analgesik non-opioid digunakan tidak hanya pada jenis operasi derajat nyeri ringan, namun terhadap operasi derajat nyeri sedang dan berat. Efektivitasnya terhadap jenis operasi nyeri sedang sebanyak 98,5\%. Efektivitas kombinasi opioid lemah dengan non-opioid digunakan terutama pada jenis operasi derajat nyeri sedang sebanyak 98,8\%.

Pada penelitian ini ternyata terdapat ketidaksesuaian antara analgesik pascaoperasi yang diberikan dan nyeri pascaoperasi. Analgesik pascaoperasi non-opioid diberikan tidak hanya nyeri ringan, tetapi diberikan juga pada nyeri sedang (131 kasus) dan nyeri berat (30 kasus). Pada analgesik pascaoperasi kombinasi opioid lemah dan non-opioid diberikan pada operasi dengan skala perkiraan nyeri ringan (49 kasus) dan berat (14 kasus). Pada analgesik pascaoperasi kombinasi opioid kuat dan non-opioid/anestesi lokal diberikan pada operasi dengan skala perkiraan nyeri ringan (10 kasus) dan sedang (14 kasus; Tabel 4).

Tabel 4 Gambaran Pilihan Obat dan Efektivitas Analgesik Pascaoperasi terhadap Jenis Operasi

\begin{tabular}{lcccccc}
\hline \multirow{2}{*}{$\begin{array}{c}\text { Skala Perkiraan } \\
\text { Nyeri Pasca- } \\
\text { operasi }\end{array}$} & \multicolumn{2}{c}{ Non-Opioid } & \multicolumn{2}{c}{$\begin{array}{c}\text { Opioid Lemah dan Non- } \\
\text { Opioid }\end{array}$} & \multicolumn{2}{c}{$\begin{array}{c}\text { Opioid Kuat dan Non- } \\
\text { Opioid/Anastesi Lokal }\end{array}$} \\
\cline { 2 - 7 } & Efektif & $\begin{array}{c}\text { Tidak } \\
\text { Efektif }\end{array}$ & Efektif & $\begin{array}{c}\text { Tidak } \\
\text { Efektif }\end{array}$ & Efektif & $\begin{array}{c}\text { Tidak } \\
\text { Efektif }\end{array}$ \\
\hline Nyeri ringan & $123(100 \%)$ & $0(0,0 \%)$ & $48(97,9 \%)$ & $1(2,0 \%)$ & $10(100 \%)$ & $0(0,0 \%)$ \\
Nyeri sedang & $129(98,5 \%)$ & $2(1,5 \%)$ & $88(98,8 \%)$ & $1(1,1 \%)$ & $14(100 \%)$ & $0(0,0 \%)$ \\
Nyeri berat & $30(100 \%)$ & $0(0,0 \%)$ & $12(85,7 \%)$ & $2(14,3 \%)$ & $11(100 \%)$ & $0(0,0 \%)$ \\
Total & $282(99,3 \%)$ & $2(0,7 \%)$ & $148(97,4 \%)$ & $4(2.6 \%)$ & $35(100 \%)$ & $0(0 \%)$ \\
\hline
\end{tabular}

Keterangan: untuk data kategorik disajikan dengan jumlah/frekuensi dan persentase, sedangkan data numerik disajikan dengan rerata, median, standar deviasi, dan range 


\section{Pembahasan}

Nyeri itu merupakan pengalaman sensorik dan emosional yang tidak menyenangkan terkait dengan kerusakan jaringan aktual atau potensial. Dampak dan persepsi rasa nyeri juga dipengaruhi oleh latar belakang perkembangan, lingkungan, dan juga sosial budaya pasien. Nyeri pascaoperasi pada anak merupakan hal yang mengganggu kualitas hidup anak. Hal tersebut juga diketahui telah menjadi keluhan yang utama pasien pediatrik setelah dilakukan prosedur operasi. ${ }^{1,4}$

Pada penelitian ini didapatkan jumlah sampel sebanyak 471 pasien. Usia rerata yang menjalani operasi elektif adalah 8,43 $\pm 5,65$. Pada hasil penelitian ini terdata jenis operasi yang paling banyak dilakukan di RSUP Dr. Hasan Sadikin Bandung adalah jenis operasi dengan skala nyeri sedang sebanyak 234 pasien $(49,7 \%)$. Dalam penerapannya dokter dan perawat melakukan anamnesis tentang nyeri, termasuk lokasi, karakteristik, onset/ durasi, frekuensi, kualitas, intensitas, atau beratnya nyeri. Terdapat beberapa hal yang dapat memengaruhi persepsi dan tingkah laku seseorang terhadap nyeri, yaitu (1) usia; (2) sosial budaya; (3) tumbuh kembang; (4) lingkungan. Penilaian rasa nyeri adalah langkah pertama dalam menentukan tata laksana nyeri yang tepat. Sayangnya, terkadang pengkajian nyeri masih dilakukan secara tidak konsisten oleh penyedia layanan kesehatan umumnya. Pada penelitian ini pengkajian nyeri yang dilakukan sesuai dengan SPO yang berlaku di RSUP Dr. Hasan Sadikin Bandung.,3

Analgesik pascaoperasi yang paling banyak dipergunakan adalah parasetamol sebanyak 279 pasien (59,2\%). Berdasar atas SPO penatalaksanaan nyeri, parasetamol tunggal dipergunakan pada nyeri ringan, sedangkan pada nyeri sedang atau berat dikombinasikan dengan opioid lemah atau opioid kuat. Hal ini menggambarkan bahwa pada penelitian ini penggunaan parasetamol tunggal tidak hanya pada pasien dengan nyeri ringan yang hanya berjumlah 182 pasien $(38,6 \%)$ sehingga tampak ketidaksesuaian antara derajat nyeri dan pilihan analgesik yang dipakai.
Efektivitas analgesik di RSUP Dr. Hasan Sadikin Bandung terhadap jenis operasi terlihat bahwa efektivitas untuk jenis operasi sedang 98,7\%; jenis operasi nyeri ringan 99,5\%; dan untuk jenis operasi berat $96,4 \%$. Efektivitas penanganan nyeri pascaoperasi tersebut belum memenuhi target rumah sakit, yaitu $100 \%$ bebas nyeri. Secara global prevalensi nyeri pascaoperasi berkisar antara $50 \%$ sampai dengan $75 \%$. Nyeri pascaoperasi yang parah pada pasien pediatrik berpotensi akan menimbulkan efek jangka panjang yang signifikan. Indikator yang menunjukkan rasa nyeri tidak terkontrol di antaranya perubahan tanda fisiologis seperti denyut jantung, laju pernapasan, tekanan darah, tekanan intrakranial, berkeringat, perubahan perilaku, penampilan, atau tingkat aktivitas anak. Nyeri akut yang tidak tertangani dengan baik dapat berkembang menjadi nyeri kronik. Oleh karena itu, terapi nyeri merupakan prioritas internasional di dalam bidang tata laksana pembedahan dan medikal pada anak.

Tata laksana nyeri pascaoperasi yang tidak baik akan menyebabkan berbagai komplikasi dan pemanjangan masa rawat. Nyeri akut yang berkembang menjadi nyeri kronik akan lebih sulit diatasi dan akan mengakibatkan penurunan kualitas hidup seseorang. Oleh karena hal tersebut maka tidak boleh satu orang pasien pun yang mengalami nyeri pascaoperasi sehingga analgesik pascaoperasi yang diberikan harus efektif pada semua pasien untuk mencapai target rumah sakit, yaitu $100 \%$ bebas nyeri. ${ }^{4-6}$

Beberapa faktor yang dapat menyebabkan ketidakefektifan analgesik pada pascaoperasi dalam menangani nyeri adalah: (1) kurangnya kemampuan tenaga medis untuk mengenali nyeri pada anak, khususnya neonatus; (2) usia anak yang belum dapat menggambarkan rasa nyeri yang dialaminya; (3) kurang pengetahuan tenaga medis mengenai nyeri; (4) terdapat nyeri sebelum operasi; (5) perbedaan pengetahuan antara tenaga medis dan pasien mengenai derajat nyeri setelah operasi; serta (6) kurangnya obat analgesik pascaoperasi. ${ }^{7,8}$

Analgesik pascaoperasi yang kurang dapat terjadi karena beberapa sebab, yaitu (1) 
pemilihan obat analgesik pascaoperasi; (2) dosis obat; (3) rute pemberian analgesik; serta (4) cara pemberian analgesik (kontinu atau berkala). Selain itu, dapat terjadi perubahan perilaku karena nyeri yang dialami, yaitu (1) cemas; (2) takut; (3) dan perubahan perilaku yang lainnya., ${ }^{2,9}$

Pada pasien dengan rentang usia 7-18 tahun didapatkan ketidakefektivan analgesik pascaoperasi yang lebih besar bila dibanding dengan kelompok usia di bawahnya, yaitu sebanyak 5 pasien $(1,7 \%)$. Hal ini mungkin disebabkan oleh kelompok usia 7-18 tahun sudah dapat melaporkan dan menggambarkan nyeri pascaoperasi. Pada kelompok anak usia di bawahnya penilaian nyeri itu lebih sulit dilakukan. Hal ini sesuai dengan penelitian yang dilakukan di Amerika pada usia tersebut sudah mampu menilai nyeri pascaoperasi yang dirasakan karena pada usia yang lebih kecil belum mampu menggambarkan dan melaporkan nyeri yang dirasakan olehnya dan kemungkinan perbedaan pengetahuan antara tenaga medis dan pasien mengenai derajat nyeri sehingga kemungkinan nyeri tersebut tidak didiagnosis dengan tepat. Hal ini mengakibatkan ketidakefektivan analgesik pascaoperasi menjadi lebih kecil sebanyak 1 pasien $(0,78 \%)$ pada usia neonatus-1 tahun dan 0 pasien $(0 \%)$ pada usia 2-6 tahun. ${ }^{4,9}$

Pada beberapa penelitian yang lain, seperti di Pakistan, analgesik pascaoperasi opioid seperti fentanil banyak diberikan pada jenis operasi berat. Hal ini tidak sesuai dengan pemberian analgesik pascaoperasi fentanil di RSUP Dr. Hasan Sadikin Bandung memberikan analgesik pascaoperasi opioid pada nyeri ringan dan sedang. Ada juga penelitian yang dilakukan di Iran, analgesik pascaoperasi kaudal dengan parasetamol pada jenis operasi sedang ternyata efektivitasnya lebih baik daripada analgesik kaudal. Penelitian ini juga dilakukan di India, hanya saja membandingkan analgesik pada pascaoperasi kaudal dengan diklofenak supositoria, ternyata hasilnya lebih baik menggunakan kaudal untuk analgesik pascaoperasi pada jenis operasi sedang. Pada penelitian ini juga terlihat bahwa efektivitas analgesik pascaoperasi sebanyak 98,7\%, hal ini masih belum memenuhi target RSUP Dr. Hasan Sadikin Bandung 100\% bebas nyeri., ${ }^{3,410,11}$

Pada penelitian ini dapat dilihat bahwa pilihan analgesik pascaoperasi yang diberikan masih banyak yang tidak sesuai dengan SPO RSUP Dr. Hasan Sadikin Bandung. Beberapa kasus operasi dengan nyeri sedang dan berat hanya mendapatkan analgesik pascaoperasi non-opioid. Tetapi, didapatkan jenis operasi dengan nyeri ringan dan sedang diberikan analgesik pascaoperasi kombinasi opioid kuat dan non-opioid/anestesi lokal. Berdasar atas SPO RSUP Dr. Hasan Sadikin Bandung seharusnya non-opioid diberikan nyeri ringan, kombinasi opioid lemah dan non-opioid diberikan pada nyeri sedang, dan kombinasi opioid kuat dan non-opioid/anestesi lokal diberikan pada nyeri berat. ${ }^{3}$

Pilihan analgesik pascaoperasi harus sesuai dengan derajat nyeri yang ditimbulkan untuk mempertimbangkan efek samping dari obat-obatan analgesik pascaoperasi, biaya perawatan dan pengobatan pasien, dan lama perawatan. Stimulasi nyeri tanpa analgesik yang tepat tidak hanya akan menyebabkan nyeri berkepanjangan, tetapi juga akan menyebabkan respons nyeri yang berlebihan. Analgesik pascaoperasi yang tepat terbukti mengurangi morbiditas dan juga mortalitas. Pilihan analgesik pascaoperasi yang tidak sesuai dapat mengakibatkan pemberian analgesia yang kurang atau analgesia yang berlebihan. Analgesik pascaoperasi yang tidak mencukupi akan mengakibatkan nyeri pascaoperasi akut yang berkepanjangan dan berkembang menjadi nyeri kronik. Nyeri akut pascaoperasi dapat menimbulkan rasa cemas, takut, dan perubahan perilaku anak yang terjadi langsung ketika rasa nyeri dirasakan oleh anak tersebut. Bila tidak teratasi, nyeri pascaoperasi akut akan berkembang menjadi nyeri kronik. Nyeri kronik yang dirasakan oleh pasien dapat berupa nyeri nosiseptik (disebabkan oleh proses inflamasi, contohnya hiperalgesia) dan nyeri neuropati (disebabkan oleh rangsangan abnormal pada saraf perifer dan sentral). Nyeri kronik lebih sulit diatasi sehingga menimbulkan banyak komplikasi yang akan menurunkan kualitas hidup. ${ }^{4,6,7,9,12}$ 
Pada pemberian analgesik pascaoperasi yang berlebihan dapat terjadi berbagai efek samping bergantung pada golongan obat yang diberikan, biaya yang meningkat karena penanganan efek samping tersebut, dan lama perawatan yang diakibatkan oleh penanganan efek samping obat tersebut. Pemberian multimodal analgesik pascaoperasi harus mempertimbangkan farmakologis tiap-tiap obat. Mekanisme kerja yang berbeda akan mengakibatkan efek samping yang terjadi juga berbeda. Efek samping yang dapat ditimbulkan akibat opioid, seperti mual, muntah, retensi urin, ileus, konstipasi, sedasi, dan depresi napas. Analgesik non-opioid seperti acetaminophen, cyclooxygenase selektif non-steroid antiinflamasi, ketamin, dan juga gabapentin memiliki efek samping, seperti hepato-renal toksisitas, gangguan koagulasi, gangguan kesadaran, sedasi. Efek samping tersebut harus menjadi pertimbangan dalam penatalaksanaan nyeri pascaoperasi. Oleh karena itu, penanganan nyeri pascaoperasi harus dilaksanakan secara bijak dengan memberikan pilihan terapi yang sesuai dengan derajat nyeri pasien. ${ }^{8,13,14}$

\section{Simpulan}

Efektivitas analgesik pascaoperasi di RSUP Dr. Hasan Sadikin Bandung periode JuniNovember 2018 masih belum memenuhi target bebas nyeri $100 \%$. Pemberian analgesik juga belum efisien karena masih banyak terdapat ketidaksesuaian antara pilihan analgesik dan derajat nyeri.

\section{Daftar Pustaka}

1. Wong C, Lau E, Palozzi L, Campbell F. Pain management in children: part 1-pain assessment tools and a brief review of nonpharmacological and pharmacological treatment options. Can Pharm J. 2012;145(5):222-7.

2. Nair S, Neil MJE. Pediatric pain: physiology, assessment, and pharmacology. ATOTW. 2013;289:1-10.

3. Sadikin RDH. Asesmen nyeri. Bandung: RSUP Dr. Hasan Sadikin; 2015.

4. Brasher C, Gafsous B, Dugue S, Thiollier A, Kinderf J, Nivoche Y, dkk. Postoperative pain management in children and infants: an update. Pediatr Drugs. 2014;13:1-12.

5. Masigati HG, Chilonga KS. Postoperative pain management outcomes among adults treated at a tertiary hospital in Moshi, Tanzania. Tanzania J Health Res. 2014;16(1):47-53.

6. Walker SM. Pain after surgery in children: clinical recommendations. Curr Opin Anaesthesiol. 2015;28(5):570-6.

7. White PF, Kehlet H. Improving postoperative pain management. Anesthesiology. 2010;5(1):112-220.

8. Punshi GD, Hamid M, Khan MA. Postoperative analgesia in children: an update. Middle East J Anesthesiol. 2009;20(3):355-62.

9. Cohen LL, Lemanek K, Blount RL, Dahlquist LM, Lim CS, Palemo TM, dkk. Evidencebased assessment of pediatric pain. J Pediatr Psychol. 2008;33(9):939-55.

10. Chetty S, Frohlich E, Penfold P, Hodgsin E, Raff M, Kluyts H, dkk. Acute pain guidelines. S Afr Pharm J. 2016;83(9):15-33.

11. Desai SA, Nanavati RN, Jasani BB, Kabra N. Comparison of neonatal pain, agitation and sedation scale with premature infant pain profile for the assessment of cute prolonged pin in neonates on assisted ventilation: a prospective observational study. IJCN. 2017;23(3):287-92.

12. Diedericks J. Postoperative pain management in the pediatric patient. 2006;48(3):37-42.

13. Lee JY, Jo YY. Attention to postoperative pain control in children. Korean J Anesthesiol. 2014;66(3):183-8.

14. Verghese ST, Hannallah RS. Acute pain management in children. J Pain Res. 2010;3:105-23. 